\title{
Effect of an Ovsynch56 protocol initiated at different intervals after insemination with or without a presynchronizing injection of gonadotropin-releasing hormone on fertility in lactating dairy cows
}

\author{
R. G. S. Bruno, ${ }^{*} \dagger^{1}$ J. G. N. Moraes, $\ddagger^{1}$ J. A. H. Hernández-Rivera, ${ }^{*}$ K. J. Lager, ${ }^{*} \dagger$ P. R. B. Silva, $\ddagger$ \\ A. L. A. Scanavez, $\ddagger$ L. G. D. Mendonça, $\ddagger$ R. C. Chebel, $\ddagger$ and T. R. Bilby*2,3 \\ *Texas A\&M AgriLife Extension and Research, Texas A\&M System, Stephenville 76401 \\ †Department of Agricultural Science, West Texas A\&M University, Canyon 79015 \\ ‡Department of Veterinary Population Medicine, University of Minnesota, St. Paul 55108
}

\begin{abstract}
The objectives of this study were to evaluate effects of 2 resynchronization protocols beginning at different intervals after artificial insemination (AI) on the pattern of return to estrus, ovarian responses, and pregnancy per $\mathrm{AI}(\mathrm{P} / \mathrm{AI})$ to reinsemination. Lactating cows from 2 dairies, located in Texas $(\mathrm{n}=2,233)$ and Minnesota $(\mathrm{n}=3,077)$, were assigned to 1 of 4 timed AI (TAI) protocols $17 \pm 3 \mathrm{~d}$ after AI. All cows were examined for pregnancy $31 \pm 3 \mathrm{~d}$ after previous AI. Cows assigned to early Ovsynch56 (E-OV56) or OV56 received the Ovsynch56 protocol starting 24 or $31 \mathrm{~d}$ after AI, respectively. Cows assigned to early GnRHGnRH-PGF ${ }_{2 \alpha}-$ GnRH (E-GGPG) or GGPG received a presynchronizing $\mathrm{GnRH}$ injection 17 or $24 \mathrm{~d}$ after AI, respectively, $7 \mathrm{~d}$ before the start of the Ovsynch56 protocol. Cows observed in estrus after enrollment were inseminated on the same day. Ovaries were examined and blood was sampled for progesterone concentration on the day of first $\mathrm{GnRH}$ and $\mathrm{PGF}_{2 \alpha}$ injection of the Ovsynch56 protocol. Pregnancy was diagnosed at 31 and $66 \mathrm{~d}$ after resynchronized AI. On the day of the first $\mathrm{GnRH}$ injection of the TAI, a higher percentage of cows on E-GGPG and GGPG protocols had a corpus luteum $(\mathrm{E}-\mathrm{GGPG}=83.8, \mathrm{GGPG}=91.2, \mathrm{E}-\mathrm{OV} 56=$ 80.4 , and OV56 $=75.5 \%$ ) and progesterone concentration $>1 \mathrm{ng} / \mathrm{mL}(\mathrm{E}-\mathrm{GGPG}=62.5, \mathrm{GGPG}=76.0$, E-OV56 $=53.6$, and OV56 $=60.8 \%$ ) than cows assigned to other protocols. However, the percentage of cows ovulating to the first $\mathrm{GnRH}$ injection of TAI was not affected by treatment. Fewer E-GGPG and more OV56 cows were reinseminated in estrus $(\mathrm{E}-\mathrm{GGPG}=23.7$, $\mathrm{GGPG}=49.0, \mathrm{E}-\mathrm{OV} 56=41.6$, and OV56 $=57.6 \%$ ). Treatment did not affect $\mathrm{P} / \mathrm{AI}$ at 31 or $66 \mathrm{~d}$ for cows
\end{abstract}

Received March 18, 2013.

Accepted September 16, 2013.

${ }^{1}$ Both authors contributed equally to this manuscript.

${ }^{2}$ Current address: Merck Animal Health, Fort Worth, TX 76107.

${ }^{3}$ Corresponding author: todd.bilby@merck.com reinseminated in estrus. However, cows reinseminated in estrus had greater P/AI at 31 (40.0 vs. 27.5\%) and $66 \mathrm{~d}$ (36.0 vs. $23.9 \%)$ than cows completing the TAI protocols. Among cows completing the TAI protocols, initiation of GGPG at $24 \mathrm{~d}$ after AI increased, whereas initiation of Ovsynch56 at $24 \mathrm{~d}$ after AI decreased P/AI at $31 \mathrm{~d}$ after reinsemination $(\mathrm{E}-\mathrm{GGPG}=30.6, \mathrm{GGPG}$ $=28.3 .0$, E-OV56 $=22.3$, and OV56 $=28.7 \%)$. Pregnancy per AI did not differ across treatment at $66 \mathrm{~d}$ after TAI $(\mathrm{E}-\mathrm{GGPG}=26.6, \mathrm{GGPG}=24.4, \mathrm{E}-\mathrm{OV} 56=$ 20.0 , and OV56 $=24.1 \%$ ). Overall, type of resynchronization protocol and protocol initiation time did not affect P/AI $66 \mathrm{~d}$ after reinsemination $(\mathrm{E}-\mathrm{GGPG}=29.7$, GGPG $=30.5$, E-OV56 $=26.1$, and OV56 $=30.4 \%$ ). In conclusion, GGPG resynchronization protocols and initiation of resynchronization protocol $24 \mathrm{~d}$ after AI reduced the number of cows reinseminated in estrus but neither the timing of initiation of resynchronization nor presynchronization with GnRH affected overall P/AI. Key words: dairy cow, 2-injection gonadotropinreleasing hormone (GnRH)-prostaglandin $2 \alpha-\mathrm{GnRH}$ (GGPG) protocol, resynchronization

\section{INTRODUCTION}

Resynchronization of cows with unknown pregnancy status has shown to be inconsistent due to the variability in stage of the estrous cycle at time of pregnancy diagnosis and resynchronization. A common practice for reinsemination of cows of unknown pregnancy status is to synchronize follicle development by initiating the resynchronization protocol $7 \mathrm{~d}$ before the nonpregnancy diagnosis with administration of $\mathrm{GnRH}$, and subsequently completing the protocol after nonpregnancy is confirmed (Chebel et al., 2003), which might advance reinsemination of nonpregnant cows. One possible concern with this protocol is that the cows are at random stages of the estrous cycle when presented for resynchronization, which may reduce ovulatory response to the first $\mathrm{GnRH}$ injection of the synchronization 
protocol (Vasconcelos et al., 1999), reducing embryo quality (Cerri et al., 2005) and pregnancy per AI (P/ AI; Chebel et al., 2006). One possible way to alleviate this issue is through presynchronization to increase the number of cows entering the resynchronization protocol between $\mathrm{d} 5$ and 10 of the estrous cycle, which has been shown to be optimal to improve pregnancy rates (Moreira et al., 2000). Silva et al. (2007) showed a significant improvement in $\mathrm{P} / \mathrm{AI}(35.2$ vs. $25.6 \%)$ and a reduction in embryo loss (7.6 vs. 17.1\%) when cows were diagnosed not pregnant and received an injection of $\mathrm{PGF}_{2 \alpha} 12 \mathrm{~d}$ before initiation of a resynchronization protocol. Cows presynchronized with $\mathrm{PGF}_{2 \alpha}$, however, had a 2-wk delay in reinsemination compared with cows not presynchronized with $\mathrm{PGF}_{2 \alpha}$, which is likely to abrogate the improvements in $\mathrm{P} / \mathrm{AI}$ on 21-d pregnancy rates.

Recently, our group conducted a study to evaluate 3 resynchronization strategies (Dewey et al., 2010). Cows were diagnosed for pregnancy $38 \pm 3 \mathrm{~d}$ after AI and those diagnosed nonpregnant started the resynchronization protocol on the same day $(\mathrm{GnRH}$ injection at nonpregnancy diagnosis, $\mathrm{PGF}_{2 \alpha}$ injection $7 \mathrm{~d}$ later, and timed AI (TAI) and GnRH injection $3 \mathrm{~d}$ later). However, one-third of the cows received a $\mathrm{GnRH}$ injection 1 wk before pregnancy diagnosis (GGPG) and another one-third of the cows received a controlled internal drug release (CIDR) insert from the day of nonpregnancy diagnosis to the day of $\mathrm{PGF}_{2 \alpha}$ injection. It was hypothesized that by treating cows with a $\mathrm{GnRH}$ injection 7 $\mathrm{d}$ before the start of the resynchronization protocol, more cows would ovulate in response to the first $\mathrm{GnRH}$ injection of the TAI protocol, and that by treating cows with a CIDR insert during the resynchronization protocol, better synchrony following the TAI protocol would be achieved. In this study, cows receiving GnRH $7 \mathrm{~d}$ before the start of the resynchronization protocol were more likely to ovulate in response to the first GnRH injection of the resynchronization protocol [number of corpora lutea $(\mathbf{C L})$ : control $=0.91, \mathrm{GGPG}=1.19$, and $\mathrm{CIDR}=0.93]$ and cows receiving the GnRH injection 7 $\mathrm{d}$ before the start of the resynchronization protocol and those receiving a CIDR during the resynchronization protocol had greater P/AI (control $=22.1$, GGPG $=$ 31.2 , and CIDR $=29.5 \%$; Dewey et al., 2010). These studies indicate that $\mathrm{P} / \mathrm{AI}$ of resynchronized cows can be improved by presynchronizing cows before the start of the resynchronization protocol. However, this study was conducted with late $(38 \pm 3 \mathrm{~d})$ nonpregnancy diagnosis only. Although several dairy herds in the United States still diagnosis nonpregnant cows via manual palpation per rectum at later stages of pregnancy (i.e., 35 to $42 \mathrm{~d}$ after AI), advancement in ultrasound technologies and use of early pregnancy diagnosis blood tests are allowing for earlier (31 $\pm 3 \mathrm{~d})$ nonpregnancy diagnosis to occur, which is gaining in popularity.

The hypotheses of the current experiment were that starting the resynchronization protocol $31 \mathrm{~d}$ after AI versus $24 \mathrm{~d}$ after AI would increase the percentage of cows reinseminated in estrus, and improve ovarian responses and P/AI of resynchronized cows. Furthermore, we hypothesized that presynchronizing cows with GnRH $7 \mathrm{~d}$ before the start of the resynchronization protocol would reduce the percentage of cows reinseminated in estrus, and improve ovarian responses and $\mathrm{P} /$ AI of resynchronized cows. The objectives of the current experiment were to compare the effects of administering the GGPG versus the Ovsynch56 resynchronization protocols initiated at different intervals after previous AI on pattern of reinsemination, ovarian responses, and $\mathrm{P} / \mathrm{AI}$ of lactating cows submitted to an early nonpregnancy diagnosis (31 $\pm 3 \mathrm{~d}$ after previous $\mathrm{AI})$.

\section{MATERIALS AND METHODS}

\section{Cows, Housing, and Diet}

The experiment was conducted at 2 different dairy farms located in Texas (site 1) and Minnesota (site 2) between February and June 2010. At site 1, primiparous and multiparous Holstein cows were housed in open corrals equipped with metal framework shade at the center of the pen, providing approximately 5 $\mathrm{m}^{2}$ of shade per cow and fresh and clean water available ad libitum. At site 2, primiparous and multiparous Jersey cows were housed separately in 4-row freestall cross-ventilated barns (240 headlocks and 260 stalls per pen). Cows were fed the same TMR throughout their lactation and had feed and water ad libitum.

Within each site, cows in all resynchronization protocols had similar diet composition and were fed twice daily as a TMR allowing $\leq 5 \%$ feed refusals daily. Diets were formulated to meet or exceed NRC (2001) recommendations for lactating mature cows producing $>40$ $\mathrm{kg} / \mathrm{d}$ (site 1 ) or $>35 \mathrm{~kg} / \mathrm{d}$ (site 2 ) of $3.5 \%$ FCM. In both sites, cows were milked twice daily and yields of milk recorded once per month by the DHIA.

Cows were monitored daily for signs of diseases, in both sites, and if any health issue was observed, cows were moved to intensive care pens and appropriate treatment was performed following dairy protocols. All study procedures involving cows were approved by the Institutional Animal Care and Use Committee of Texas A\&M University (College Station) and the University of Minnesota (St. Paul).

\section{Treatments}

Treatments consisted of 2 resynchronization protocols (GGPG and Ovsynch56) initiated at different 


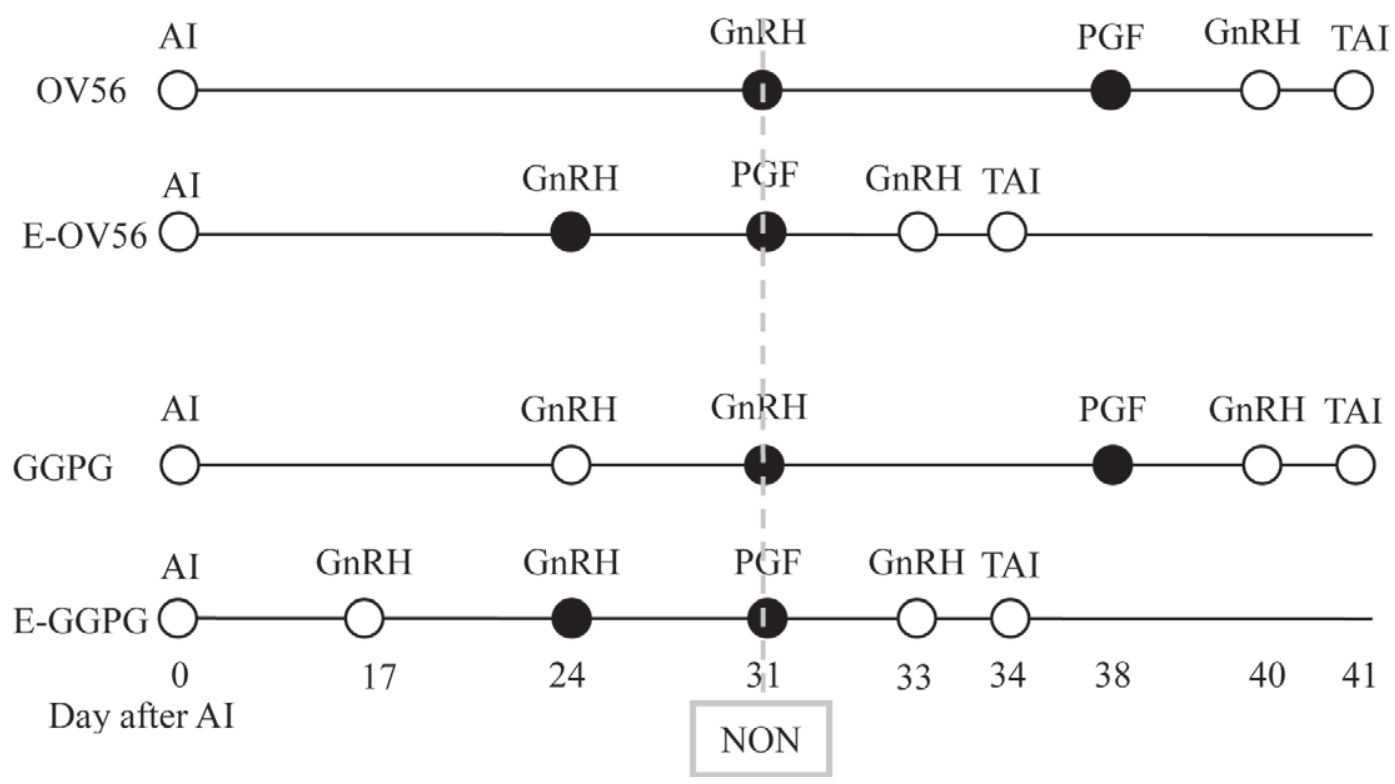

Figure 1. Diagram of study activities. OV56 = Ovsynch56 ( GnRH injection, $\mathrm{PGF}_{2 \alpha}$ injection $7 \mathrm{~d}$ later, GnRH injection $56 \mathrm{~h}$ later, and TAI $16 \mathrm{~h}$ later) starting at $31 \mathrm{~d}$ after previous AI; E-OV56 = early OV56 (Ovsynch56 starting at $24 \mathrm{~d}$ after previous AI); GGPG = presynchronizing injection of GnRH at $24 \mathrm{~d}$ after previous AI followed $7 \mathrm{~d}$ later by the Ovsynch56 protocol; E-GGPG = early GGPG (presynchronizing injection of $\mathrm{GnRH}$ at $31 \mathrm{~d}$ after previous AI followed by the Ovsynch56 protocol $7 \mathrm{~d}$ later); NON = nonpregnancy diagnosis; GnRH $=100 \mu \mathrm{g}$ of gonadorelin sterile solution (Cystorelin, $50 \mu \mathrm{g} / \mathrm{mL}$; Merial Animal Health, Summit, NJ); PGF $=500 \mu \mathrm{g}$ of prostaglandin (Estrumate, $250 \mu \mathrm{g} / \mathrm{mL}$ of cloprostenol sodium; Merck Animal Health, De Soto, KS); TAI = timed AI; solid black circles = blood sample and ultrasound scan.

times after AI. To be eligible for study enrollment, cows had to have at least 1 AI between 14 and $20 \mathrm{~d}$ (17 $\pm 3 \mathrm{~d}$ ) before the enrollment date. Cows fulfilling the enrollment criterion were then blocked by parity, number of AI, DIM, and predicted 305-d milk production and were randomly assigned to 1 of 4 resynchronization protocols (Figure 1). Cows assigned to the early GGPG protocol (E-GGPG) received a presynchronizing 100- $\mu \mathrm{g}$ GnRH injection (Cystorelin; $50 \mu \mathrm{g} / \mathrm{mL}$ of gonadorelin diacetate tetrahydrate; Merial Animal Health, Duluth, GA) at the time of study enrollment (17 $\pm 3 \mathrm{~d}$ after previous AI) followed by the Ovsynch56 protocol $[100 \mu \mathrm{g}$ of $\mathrm{GnRH}$, followed $7 \mathrm{~d}$ later by 500 $\mu \mathrm{g}$ of $\mathrm{PGF}_{2 \alpha}$ (Estrumate; $250 \mu \mathrm{g} / \mathrm{mL}$ of cloprostenol sodium; Merck Animal Health, De Soto, KS), followed $56 \mathrm{~h}$ later by $\mathrm{GnRH}$, and followed $16 \mathrm{~h}$ later by TAI 7 $\mathrm{d}$ later, with cows inseminated at fixed time $3 \mathrm{~d}$ after nonpregnancy diagnosis. Cows assigned to the GGPG protocol received a presynchronizing $\mathrm{GnRH}$ injection 7 $\mathrm{d}$ after study enrollment ( $24 \pm 3 \mathrm{~d}$ after previous AI) and began the Ovsynch56 protocol $7 \mathrm{~d}$ later at the time of nonpregnancy diagnosis $(31 \pm 3 \mathrm{~d}$ after previous AI). Cows assigned to the early Ovsynch56 (E-OV56) started the resynchronization protocol Ovsynch56 $1 \mathrm{wk}$ after enrollment ( $24 \pm 3$ d after previous AI). Finally, cows assigned to the Ovsynch56 protocol (OV56) started the Ovsynch56 protocol at nonpregnancy diagnosis $(31 \pm 3 \mathrm{~d}$ after previous $\mathrm{AI})$. Cows were allowed to be artificially inseminated on detected estrus at any time during the resynchronization protocol. In both sites, estrus detection was performed daily based on the removal of tail chalking (Macmillan et al., 1988) using paint sticks (All-Weather Paintstik, livestock marker; LA-CO Industries Inc., Elk Grove Village, IL) and AI were performed at the same morning as estrus was detected by experienced technicians (Figure 1).

\section{BCS, Ovarian Structures, Blood Collection, and Pregnancy Diagnosis}

All cows were scored for body condition using a 5-point scale according to Ferguson et al. (1994) at nonpregnancy diagnosis (2 wk after study enrollment). A subsample of 444 cows (251 multiparous and 193 primiparous) from both sites had their ovaries examined by ultrasonography on the day of the first $\mathrm{GnRH}$ injection and again at $\mathrm{PGF}_{2 \alpha}$ injection of the TAI protocol to determine the response to protocol injections. A realtime ultrasound scanner (Ibex Pro; E. I. Medical Imaging, Loveland, CO) equipped with 7.5-Mhz rectal linear probe was used for nonpregnancy diagnosis. Ovulation to the first GnRH injection of the TAI protocol was characterized by the presence of at least 1 follicle larger than $10 \mathrm{~mm}$ at the time of first $\mathrm{GnRH}$ injection of the protocol, which was replaced by a corpus luteum $(\mathbf{C L})$ at the time of $\mathrm{PGF}_{2 \alpha}$ injection. Blood samples $(10 \mathrm{~mL})$ 
were also collected at the same time points from the same subsample of cows by puncture of the coccygeal vein or artery into evacuated tubes (Vacutainer; Becton Dickinson, Franklin Lakes, NJ). Immediately after collection, samples were placed on ice and processed at the laboratory within $4 \mathrm{~h}$ of collection. Blood tubes were centrifuged at $2,000 \times g$ for 15 min for plasma separation. Plasma was frozen at $-25^{\circ} \mathrm{C}$ and later analyzed for progesterone $\left(\mathbf{P}_{4}\right)$ by a solid-phase RIA using a commercial kit (Coat-A-Count; Diagnostic Products Corp., Los Angeles, CA). The assay sensitivity was $0.1 \mathrm{ng} / \mathrm{mL}$ and the intra- and interassay coefficients of variation were 5.4 and $7.9 \%$, respectively.

Pregnancy status was diagnosed at $31 \pm 3 \mathrm{~d}$ after AI by transrectal ultrasonography of the reproductive tract. Observation of embryonic fluid, embryo, and embryonic heartbeat were used as determinants of pregnancy. Pregnancies were reconfirmed at $66 \pm 3 \mathrm{~d}$ after AI by transrectal palpation of the reproductive tract. Cows diagnosed pregnant at $31 \pm 3 \mathrm{~d}$ but not pregnant at $66 \pm 3 \mathrm{~d}$ after AI were considered to have had embryo/fetal loss. Pregnancy rate was defined as the percentage of eligible cows that become pregnant within each week of the experiment. It was calculated on a weekly basis from the study enrollment until the week of fixed-time AI in each treatment.

\section{Statistical Analyses}

The experimental design was a randomized complete block design (Kuehl, 1994) in which cows were blocked according to parity, number of AI, DIM, and predicted 305-d milk production. Within each block, cows were randomly assigned weekly to 1 of 4 resynchronization protocols with a $2 \times 2$ factorial arrangement, with resynchronization protocol (Ovsynch56 vs. GGPG) and time of initiation of the resynchronization protocol (24 vs. $31 \mathrm{~d}$ after AI) as the main factors. A sample size calculation was performed (Minitab Inc., 2000) to estimate the number of experimental units required to detect $7 \%$ units difference in $\mathrm{P} / \mathrm{AI}$ with $95 \%$ confidence $(\alpha=0.05)$ and $80 \%$ protection against a type II error $(\beta=0.20)$, giving that $\mathrm{P} / \mathrm{AI}$ ranges from 30 to $40 \%$. Furthermore, the number of experimental units provided enough pregnant cows at $66 \pm 3 \mathrm{~d}$ after AI to detect statistical significance with a $8 \%$ unit difference in pregnancy loss among treatments $(\alpha=0.05 ; \beta=$ $0.20)$.

Plasma $\mathrm{P}_{4}$ concentration, a normal distributed data, was transformed into 2 categories (high or low concentration) following a binomial distribution. A concentrations higher than $1 \mathrm{ng} / \mathrm{mL}$ was defined as high and a concentration less than or equal to $1 \mathrm{ng} / \mathrm{mL}$ was defined as low plasma $\mathrm{P}_{4}$ concentration.
Binomially distributed data such as reinsemination during TAI protocol, $\mathrm{P} / \mathrm{AI}$, presence of CL at the first GnRH injection of the TAI protocol, $\mathrm{P}_{4}$ levels (high or low) at the first GnRH injection of the TAI protocol, and ovulation to the first GnRH injection of the TAI protocol were analyzed by logistic regression using PROC LOGISTIC of SAS (SAS 9.2; SAS Institute, 2008). A backward stepwise regression model was used (Allison, 1999), and the full model included the effects of resynchronization protocol, protocol initiation time, site, parity, BCS, milk yield on previous lactation, number of inseminations at enrollment, and the interactions between treatment and the respective explanatory variables. Variables were continuously removed from the model by the Wald statistic criterion if the significance was at $P>0.20$. The Akaike information criterion was used to define the best model to be used for each dependent variable analysis. Both protocol and site were forced to remain in each model even if backward elimination suggested to be removed.

The interval between study enrollment and reinsemination was analyzed by the nonparametric method Kruskal-Wallis rank test to identify differences across resynchronization protocols initiated at different times. Median days between study enrollment and subsequent AI was also analyzed by survival analysis using the product limit method of the Kaplan-Meier model (Kaplan and Meier, 1958) by the LIFETEST procedure to illustrate these interval differences across resynchronization programs initiated at different times. Differences with $P \leq 0.05$ were considered significant and $0.05<P$ $\leq 0.10$ were designated as a tendency to differ.

\section{RESULTS}

A total of 2,934 lactating dairy cows fulfilled the enrollment criterion (1,368 cows from Texas and 1,606 from Minnesota sites) and were enrolled in the study. The average milk yield at study enrollment was not different across treatments $(\mathrm{E}-\mathrm{GGPG}=32.3 \pm 0.33$, GGPG $=32.1 \pm 0.35$, E-OV56 $=32.1 \pm 0.36$, and OV56 $=31.7 \pm 0.29 \mathrm{~kg} / \mathrm{d}$ ). The BCS at time of nonpregnancy diagnosis did not differ among treatments $(\mathrm{E}-\mathrm{GGPG}=3.00, \mathrm{GGPG}=2.75, \mathrm{E}-\mathrm{OV} 56=3.00$, and OV56 $=3.00$ ) and within each treatment, the median BCS for multiparous and primiparous cows were 2.75 and 3.00, respectively.

\section{Estrus Detection and Pattern of Reinsemination}

In total, $44.1 \%$ of all cows were observed in estrus and inseminated before completing the TAI protocol. Cows assigned to the GGPG protocols were less likely $(P<0.001)$ to be reinseminated in estrus during the 
resynchronization protocol than cows assigned to the Ovsynch56 protocols, regardless of protocol's initiation time $[\mathrm{GGPG}=37.1 \%$ and Ovsynch $56=50.6 \%$; adjusted odds ratio $(\mathbf{A O R})=0.58 ; 95 \% \mathrm{CI}=0.50$ to 0.67 . Within each resynchronization protocol (Ovsynch56 and GGPG), cows initiated the resynchronization protocol at $24 \mathrm{~d}$ after AI (E-OV56 and E-GGPG) and were less likely $(P<0.001)$ to be identified in estrus before the completion of the TAI protocol (32.7 vs. 53.6\%; $\mathrm{AOR}=0.42 ; 95 \% \mathrm{CI}=0.36$ to 0.49$)$ than cows assigned to initiate protocol at $31 \mathrm{~d}$ after AI (Figure 2). An interaction between resynchronization protocol and time of protocol initiation was detected in which the resynchronization protocol initiated at $24 \mathrm{~d}$ after AI resulted in a more pronounced decrease $(P<0.01)$ in the percentage of reinseminations in estrus during the resynchronization protocol than cows submitted to the Ovsynch56 protocol (Figure 2). The median day interval between study enrollment and subsequent AI was $17 \mathrm{~d}$ for cows assigned to the E-GGPG and E-OV56 protocols, whereas the GGPG and OV56 were 21 and $12 \mathrm{~d}$, respectively (Figure 3 ).

\section{Protocol Completion and Ovarian Responses to Protocol}

Among all cows enrolled in this study, 55.9\% completed their respective resynchronization protocols and were inseminated at fixed time. For these cows, the average milk yield at study enrollment was not different $(P=0.45)$ across treatments (OV56 $=31.7 \pm 0.46$, $\mathrm{E}-\mathrm{OV} 56=32.4 \pm 0.49, \mathrm{GGPG}=32.7 \pm 0.48$, and $\mathrm{E}-\mathrm{GGPG}=32.1 \pm 0.42 \mathrm{~kg} / \mathrm{d}$ ) and the median BCS did not differ among treatments $(\mathrm{E}-\mathrm{GGPG}=3.00, \mathrm{GGPG}$

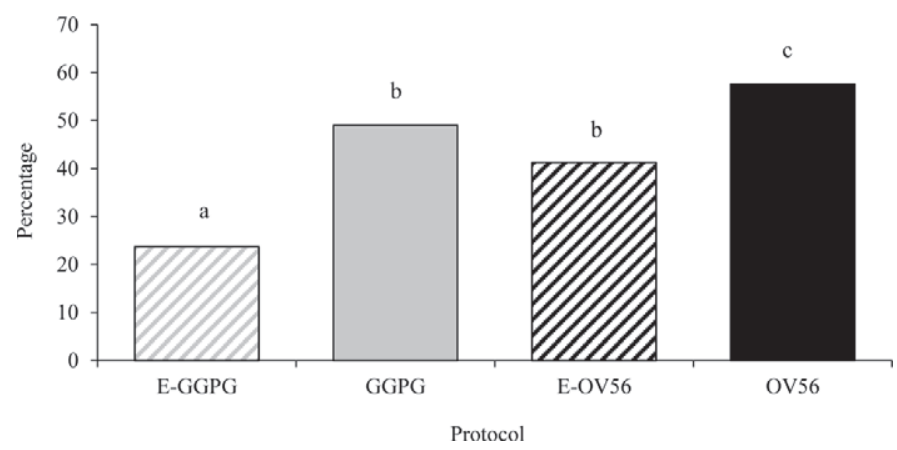

Figure 2. Percentage of cows reinseminated on detected estrus. OV56 = Ovsynch56 (GnRH injection, $\mathrm{PGF}_{2 \alpha}$ injection $7 \mathrm{~d}$ later, $\mathrm{GnRH}$ injection $56 \mathrm{~h}$ later, and TAI $16 \mathrm{~h}$ later) starting at $31 \mathrm{~d}$ after previous AI; E-OV56 = early OV56 (Ovsynch56 starting at $24 \mathrm{~d}$ after previous $\mathrm{AI}) ; \mathrm{GGPG}=$ presynchronizing injection of $\mathrm{GnRH}$ at $24 \mathrm{~d}$ after previous AI followed $7 \mathrm{~d}$ later by the Ovsynch 56 protocol; E-GGPG = early GGPG (presynchronizing injection of GnRH at $31 \mathrm{~d}$ after previous AI followed by the Ovsynch56 protocol $7 \mathrm{~d}$ later). Different letters $(\mathrm{a}-\mathrm{c})$ indicate statistical differences of $P<0.01$.
$=2.75, \mathrm{E}-\mathrm{OV} 56=3.00$, and OV56 $=2.75)$ and within each treatment, the median BCS for multiparous and primiparous cows were 2.75 and 3.00, respectively.

On the day of the first GnRH injection (i.e., $7 \mathrm{~d}$ before $\mathrm{PGF}_{2 \alpha}$ injection) of the resynchronization protocol (d 24 for E-OV56 and E-GGPG; d 31 for OV56 and GGPG), the percentage of cows that had a CL was greater $(P<0.01)$ for cows receiving the GGPG compared with cows assigned to the Ovsynch56 protocols, regardless of initiation time $(\mathrm{GGPG}=87.4$ and Ovsynch56 $=77.9 \%$, respectively). The percentage of cows with CL on the day of the first GnRH injection of the resynchronization protocol did not differ $(P=$ $0.40)$ between protocols initiated at 24 or $31 \mathrm{~d}$ after previous AI ( 82.0 and $84.1 \%$, respectively). However, an interaction between resynchronization protocol and its initiation time revealed an increased percentage of cows with CL at the time of the first GnRH injection for the Ovsynch56 protocol compared with GGPG when protocols were initiated $24 \mathrm{~d}$ after AI.

On the day of the first GnRH injection of the TAI protocol, $64.0 \%$ of the cows had $\mathrm{P}_{4}$ concentrations $>1$ $\mathrm{ng} / \mathrm{mL}$. The percentage of cows with plasma $\mathrm{P}_{4}$ concentrations $>1 \mathrm{ng} / \mathrm{mL}$ was greater $(P<0.01)$ for cows assigned to the GGPG protocols compared with cows receiving the Ovsynch56 protocols, regardless of initiation time $(\mathrm{GGPG}=69.4$ vs. Ovsynch $56=57.3 \%)$. Protocols initiated at $24 \mathrm{~d}$ after AI resulted in a decreased $(P=0.02)$ percentage of cows with plasma $\mathrm{P}_{4}$ concentrations $>1 \mathrm{ng} / \mathrm{mL}$ at the time of the first $\mathrm{GnRH}$ injection of the TAI protocol compared with cows that initiated the resynchronization protocol at $31 \mathrm{~d}$ after AI (58.8 and $69.2 \%$, respectively).

At the time of the $\mathrm{PGF}_{2 \alpha}$ injection, the percentage of cows with plasma $\mathrm{P}_{4}$ concentration $>1 \mathrm{ng} / \mathrm{mL}$ and the percentage of cows with at least 1 visible CL was not affected by type of resynchronization method or its initiation time (Table 1). The percentage of cows that ovulated in response to the first $\mathrm{GnRH}$ injection of the resynchronization protocol was not different among resynchronization protocol or protocol initiation time (Table 1).

\section{P/Al and Pregnancy Loss}

Cows inseminated on detected estrus had increased $(P<0.01) \mathrm{P} / \mathrm{AI}$ at 31 and $66 \mathrm{~d}$ after $\mathrm{AI}$ than cows receiving TAI (Figure 4). Risk of pregnancy at 31 and $66 \mathrm{~d}$ after reinsemination was not affected by the resynchronization protocol or its initiation time for cows reinseminated on detected estrus $(P>0.21)$. However, for cows receiving TAI, an interaction between resynchronization protocol and protocol initiation time was detected $(P=0.05)$, with risk of pregnancy at 31 


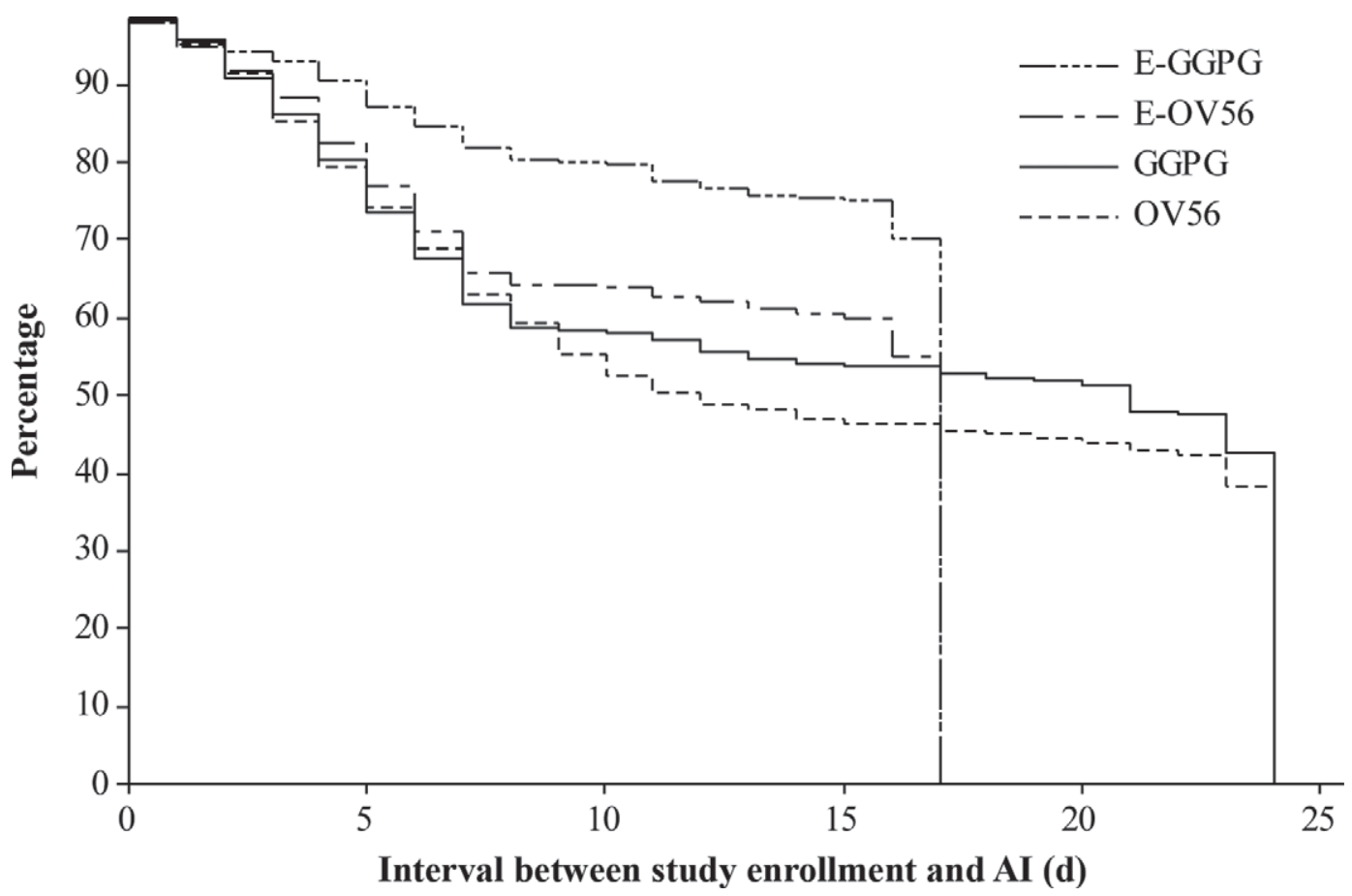

Figure 3. Kaplan-Mayer survival analysis illustrating the effect of resynchronization programs on the median day interval between study enrollment and subsequent AI for cows submitted to 2 resynchronization programs starting at 2 different initiation times (E-GGPG $=17$, E-OV56 $=17, \mathrm{GGPG}=21$, and OV56 $=12 \mathrm{~d} ; \mathrm{P}<0.001)$. OV56 $=$ Ovsynch56 $\left(\mathrm{GnRH}\right.$ injection, $\mathrm{PGF}_{2 \alpha}$ injection $7 \mathrm{~d}$ later, GnRH injection $56 \mathrm{~h}$ later, and TAI $16 \mathrm{~h}$ later) starting at $31 \mathrm{~d}$ after previous AI; E-OV56 = early OV56 (Ovsynch56 starting at $24 \mathrm{~d}$ after previous AI); GGPG = presynchronizing injection of $\mathrm{GnRH}$ at $24 \mathrm{~d}$ after previous AI followed $7 \mathrm{~d}$ later by the Ovsynch56 protocol; E-GGPG = early GGPG (presynchronizing injection of GnRH at $31 \mathrm{~d}$ after previous AI followed by the Ovsynch56 protocol $7 \mathrm{~d}$ later).

d after AI being increased with the GGPG protocol and decreased with the Osynch56 protocol when resynchronization was initiated at $24 \mathrm{~d}$ after AI (Table $2)$. When pregnancy was assessed again $66 \mathrm{~d}$ after reinsemination, the risk of pregnancy was not affected by the resynchronization protocol, protocol initiation time, or its interaction (Table 2). When data from cows reinseminated on detected estrus and at fixed time was combined (overall $\mathrm{P} / \mathrm{AI}$ ), a tendency for increased $\mathrm{P} /$ $\mathrm{AI}$ at $31 \mathrm{~d}$ after reinsemination was observed for protocols initiated at $24 \mathrm{~d}$ after $\mathrm{AI}(P=0.07)$ but no longer observed $(P=0.11)$ when pregnancy was assessed at 66 $\mathrm{d}$ after reinsemination (Table 2 ).

The risk of pregnancy loss between d 31 and 66 of gestation did not differ between treatments. Pregnancy loss was not influenced by type of protocol (Ovsynch56 or GGPG) or protocol initiation time (24 or $31 \mathrm{~d}$ after AI). However, cows reinseminated on detected estrus had a tendency to have fewer pregnancy losses between 31 and $66 \mathrm{~d}$ of gestation (AI upon estrus detection $=$ 8.3 vs. $\mathrm{TAI}=11.8 \% ; \mathrm{AOR}=0.68 ; 95 \% \mathrm{CI}=0.43$ to $1.05 ; P=0.08)$.

Cows enrolled in the E-GGPG treatment had decreased pregnancy rate from 0 to $7 \mathrm{~d}$ after enrollment compared with the other resynchronization protocols, whereas the OV56 protocol had increased pregnancy rate from 8 to $14 \mathrm{~d}$ after enrollment than other protocols. From 15 to $21 \mathrm{~d}$ after enrollment, cows in the E-GGPG treatment had increased pregnancy rate and cows in the OV56 and GGPG treatments had decreased pregnancy rate compared with cows in the E-OV56 treatment. Pregnancy rate did not differ between OV56 and GGPG treatments from 22 to $28 \mathrm{~d}$ after enrollment (Table 2).

\section{DISCUSSION}

Hormonal manipulation of the estrous cycle using GnRH and $\mathrm{PGF}_{2 \alpha}$ has been widely implemented as resynchronization strategies to decrease the interval between $\mathrm{AI}$ in cows that have failed to conceive to a previous AI. Among cows not conceiving, less than $50 \%$ display estrus and are reinseminated before nonpregnancy diagnosis (Chebel et al., 2006; Cerri et al., 2009) and few display estrus after receiving the first injection of the resynchronization protocol (Dewey et al., 2010). In this study, $44.1 \%$ of all cows were observed in estrus between $17 \mathrm{~d}$ after previous AI and the completion of the TAI protocol. Treatment of cows with a presynchronizing GnRH and early initiation of the resynchronization protocol decreased expression of estrus. This decrease 


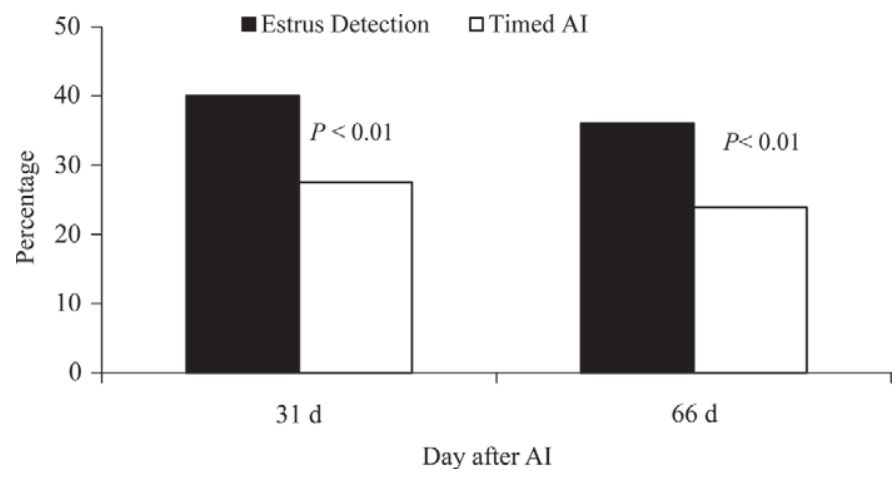

Figure 4. Pregnancy per AI at 31 and $66 \mathrm{~d}$ after reinsemination $(P<0.01)$ in cows reinseminated upon estrus detection (black bars) or timed AI (white bars), regardless of resynchronization protocol or its initiation time.

in estrus expression during TAI protocols incorporating a presynchronizing $\mathrm{GnRH}$ injection was expected and agrees with previous findings from our laboratory (Bruno et al., 2012; Mendonça et al., 2012; Chebel et al., 2013), with one of the consequences being an increased percentage of cows receiving TAI. Lopes et al. (2013), evaluating similar protocols but initiated at 32 or $39 \pm$ $3 \mathrm{~d}$ after AI, identified similar estrus return patterns as observed in the current study when resynchronization with GGPG or Ovsynch56 protocols were compared. However, in the Lopes et al. (2013) study, only $22 \%$ of AI was performed upon estrus detection compared with $44.1 \%$ observed within the current study. The difference in the number of cows detected in estrus can be attributed to a variety of possible management differences among sites, such as protocol initiation time, type of estrus detection, flooring, level of milk production, and breed, as the proportion of cows AI upon estrus detection for the current study was similar between the study sites. In addition, Giordano et al. (2012) also conducted a study using the GGPG protocol compared with a control with no presynchronization injection or the use of human chorionic gonadotropin 1 wk before the start of the synchronization program. Within the Giordano et al. (2012) study, no difference was observed in fertility between the control $(24.0 \% \mathrm{P} / \mathrm{AI})$ and GGPG (28.5\% P/AI) groups but there was an improvement when using human chorionic gonadotropin $(31.3 \% \mathrm{P} / \mathrm{AI})$ to improve fertility. However, estrus detection was not evaluated within their study, which would change the type of population of cows receiving the TAI protocol (i.e., more concentrated population of anovular, cystic, and anestrus cows) and provides an explanation for the difference in results compared with the current study.

The inhibitory effect on estrus expression exerted by GnRH might be associated with the fact that giving an

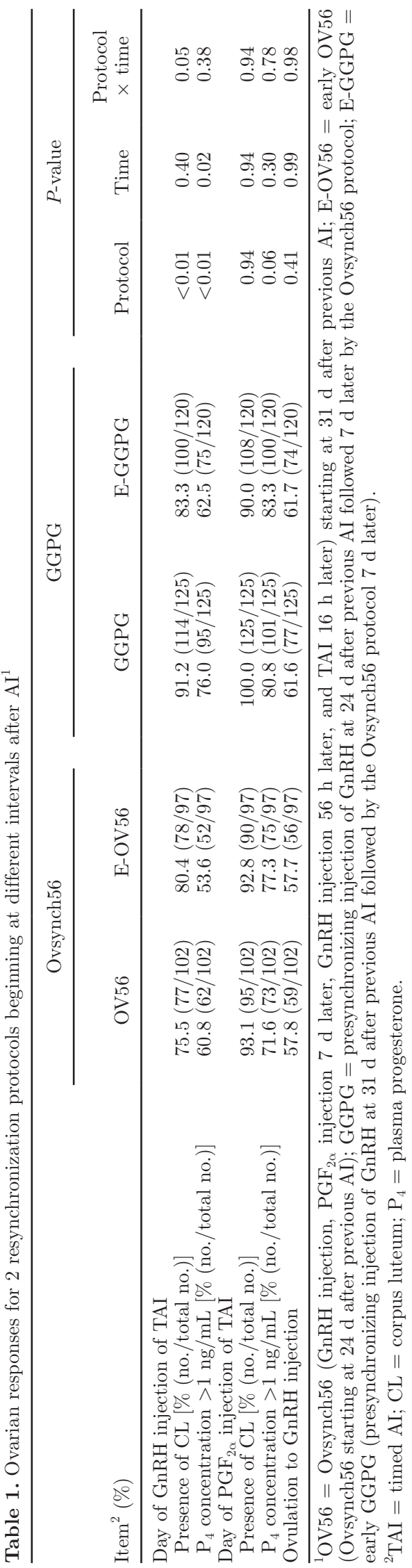

Journal of Dairy Science Vol. 97 No. 1, 2014 
Table 2. Pregnancy per AI in cows inseminated on detected estrus and at fixed time ${ }^{1}$

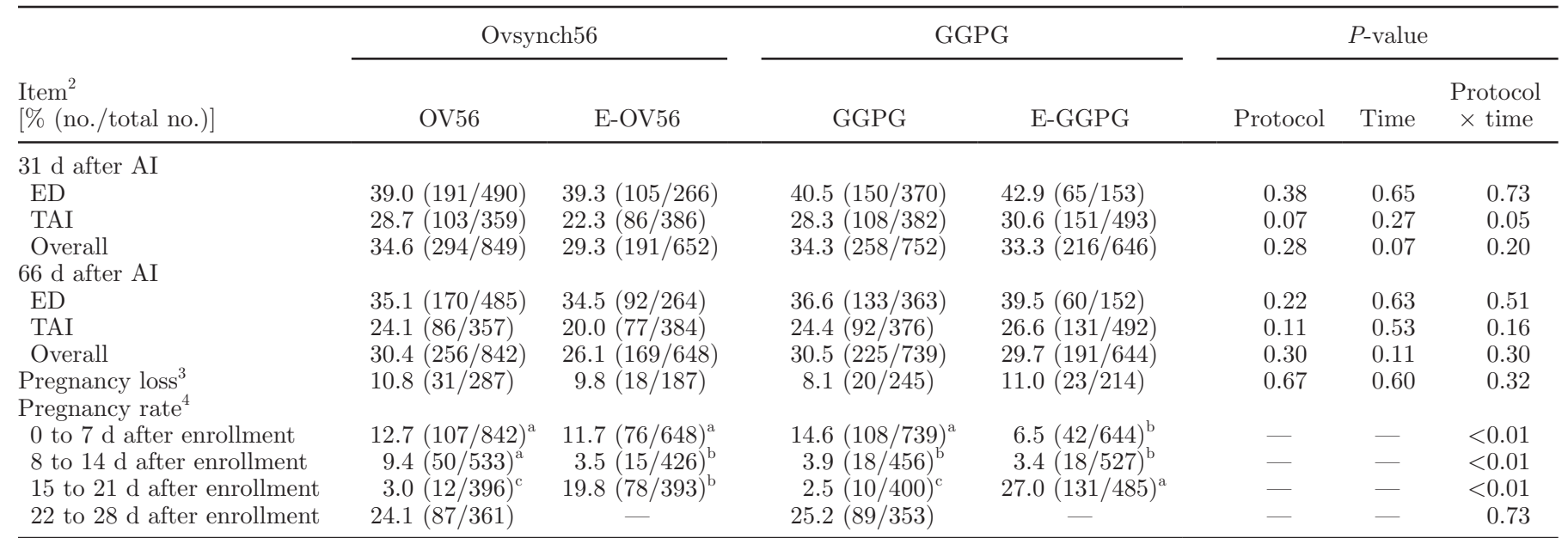

${ }^{\mathrm{a}-\mathrm{c}}$ Values within a row with different superscripts differ $(P<0.10)$.

${ }^{1}$ OV56 = Ovsynch56 (GnRH injection, $\mathrm{PGF}_{2 \alpha}$ injection $7 \mathrm{~d}$ later, $\mathrm{GnRH}$ injection $56 \mathrm{~h}$ later, and TAI $16 \mathrm{~h}$ later $)$ starting at $31 \mathrm{~d}$ after previous AI; E-OV56 = early OV56 (Ovsynch56 starting at $24 \mathrm{~d}$ after previous AI); GGPG = presynchronizing injection of GnRH at $24 \mathrm{~d}$ after previous AI followed $7 \mathrm{~d}$ later by the Ovsynch56 protocol; E-GGPG = early GGPG (presynchronizing injection of GnRH at $31 \mathrm{~d}$ after previous AI followed by the Ovsynch56 protocol 7 d later).

${ }^{2} \mathrm{ED}=$ estrus detection; $\mathrm{TAI}=$ timed $\mathrm{AI}$.

${ }^{3}$ Pregnancy loss between 31 and $66 \mathrm{~d}$ after AI.

${ }^{4}$ Pregnancy rate at $66 \mathrm{~d}$ after AI.

injection of $100 \mu \mathrm{g}$ of $\mathrm{GnRH} 7 \mathrm{~d}$ before the resynchronization protocol initiation induced ovulation of follicles $\geq 10 \mathrm{~mm}$ in diameter, resulting in the formation of a new CL (Ryan et al. 1991). Moreover, GnRH can directly affect follicle development by downregulating the expression of aromatase in granulosa cells, reducing the secretion of estradiol by the dominant follicle (Fitzpatrick et al., 1997), thereby inhibiting estrus expression.

It is also important to mention that the rate at which cows were reinseminated was not only affected by the presynchronizing $\mathrm{GnRH}$ injection but it was also affected by the time of protocol initiation, with a remarkable decreased estrus expression among cows receiving the presynchronizing GnRH at $17 \mathrm{~d}$ after AI (E-GGPG) and increased estrus expression in cows starting the TAI protocol without presynchronization and at $31 \mathrm{~d}$ after AI (OV56). The plausible explanation for the negative effect on estrus expression may be due to the fact that cows submitted to the E-GGPG protocol received 2 injections of $\mathrm{GnRH}$ before the nonpregnancy diagnosis (i.e., 17 and 24 d post-AI), whereas cows submitted to the OV56 did not receive any presynchronization and received TAI $10 \mathrm{~d}$ after nonpregnancy diagnosis, increasing the period for cows to be observed in estrus.

The increased percentage of cows with $\mathrm{CL}$ and $\mathrm{P}_{4}$ concentrations $>1 \mathrm{ng} / \mathrm{mL}$ at the initiation of the resynchronization protocols also indicates a possible increase in ovulation in response to the presynchronizing $\mathrm{GnRH}$ injection compared with those protocols without pre- synchronization. These findings are in agreement with other studies in which the effect of the presynchronizing $\mathrm{GnRH}$ injection on ovarian structures was evaluated (Dewey et al., 2010; Alkar et al., 2011; Bruno et al., 2012) and have been responsible for improvements in fertility. The effect of $\mathrm{P}_{4}$ on the follicle, embryo, and fetus have been demonstrated by others (Mann and Lamming, 2001; Mann et al., 2003), with increased fertility being reported when elevated concentrations of $\mathrm{P}_{4}$ were observed during the estrous cycle preceding AI (Folman et al., 1973). Most recently, Denicol et al. (2012) demonstrated an increased likelihood for pregnancy when a synchronized follicular wave developed under high $\mathrm{P}_{4}$ concentrations. This improvement in fertility, due to elevated concentrations of $\mathrm{P}_{4}$, has been associated with improvements in oocyte (Pfeifer et al., 2009) and embryo quality (Rivera et al., 2011).

Progesterone concentration at the time of the $\mathrm{PGF}_{2 \alpha}$ injection of the resynchronization protocol was not different among treatments, which may be a consequence of the lack of difference in the percentage of cows that ovulated in response to the first GnRH injection of the resynchronization protocol. This finding was unexpected and differs from other experiments (Dewey et al., 2010; Giordano et al., 2012; Lopes et al. 2013). We speculate that the divergence in outcomes within these studies could be due to the timing of resynchronization initiation. Resynchronization protocols in the Dewey et al. (2010) study started on d 39 and within the Lopes 
et al. (2013) study, the protocols began on d 32 or 39 after previous AI. However, within the current study, resynchronization protocols began at either 24 or $31 \mathrm{~d}$ after previous AI, which could place cows at different stages of the follicular wave at the time of the $\mathrm{GnRH}$ injection. Cows reinseminated on detected estrus had increased $\mathrm{P} / \mathrm{AI}$ compared with cows reinseminated at fixed time, regardless of resynchronization treatment. Pregnancy per AI did not differ among treatments when all reinseminations were analyzed together. This increase in fertility of cows reinseminated on detected estrus has been reported by others (Kasimanickam et al., 2005; Bruno et al., 2012) and is likely to be the result of efficient and accurate estrus detection.

A tendency $(P=0.07)$ for increased $\mathrm{P} / \mathrm{AI}$ at $31 \mathrm{~d}$ after AI was observed for cows receiving the GGPG compared with cows receiving the Ovsynch56 protocol. Moreover, an interaction between type of resynchronization protocol and its initiation time was identified $(P$ $=0.05)$ in which initiation of the Ovsynch56 protocol at $24 \mathrm{~d}$ after AI decreased, whereas initiation of the GGPG resynchronization protocol at $24 \mathrm{~d}$ after AI increased $\mathrm{P} / \mathrm{AI}$ at $31 \mathrm{~d}$ after $\mathrm{AI}$ compared with cows initiating the protocols at $31 \mathrm{~d}$ after AI. However, no difference was observed at $66 \mathrm{~d}$ after reinsemination. Different than our results, Dewey et al. (2010) reported an improvement in $\mathrm{P} / \mathrm{AI}$ when a $\mathrm{GnRH}$ injection was administered $7 \mathrm{~d}$ before the initiation of the TAI and related this improvement in $\mathrm{P} / \mathrm{AI}$ to the increased percentage of cows ovulating to the first $\mathrm{GnRH}$ injection of the TAI protocol, which was not observed in the current study. Similar to our results, Alkar et al. (2011) also reported no improvement in fertility when a presynchronized GnRH injection was administered 7 $\mathrm{d}$ before the TAI protocol initiation. The reasons are still unclear for these differences in responses in fertility to protocols in which a GnRH injection was used for presynchronization. This variation in responses to the presynchronizing $\mathrm{GnRH}$ injection may be associated with different stages of the follicular wave at the time when a presynchronizing GnRH injection is administered, as the interval between previous $\mathrm{AI}$ and $\mathrm{GnRH}$ injection for all 3 studies was different. Also, different from other studies, within the current study, cows were allowed to be artificially inseminated within the protocol when signs of estrus were observed, leading to a large percentage of cows submitted to TAI being subfertile cows, which can affect the outcome results.

\section{CONCLUSIONS}

Pregnancy per AI of dairy cows subjected to Ovsynch56 or GGPG resynchronization programs was not affected by type of protocol or by intervals between previous AI and protocol initiation time. However, the percentage of cows AI on detected estrus was reduced when the resynchronization protocol started earlier and also when a presynchronizing GnRH injection was administered $7 \mathrm{~d}$ before the resynchronization protocol initiation. Furthermore, cows reinseminated on detected estrus had increased P/AI compared with cows submitted to TAI. Dairy farms with good estrus detection should prioritize resynchronization programs that allow more cows to be reinseminated on detected estrus, as higher fertility and reduced cost and labor are associated with these programs, thereby reducing the interval between AI.

\section{ACKNOWLEDGMENTS}

This research was partly supported by the Kilgore Research Center Competitive Grants Program from the West Texas A\&M University (Canyon) and Select Sires Inc. (Plain City, OH). The authors also thank Merial Animal Health (Summit, NJ) for providing the Cystorelin and Merck Animal Health (De Soto, KS) for providing the Estrumate sterile solutions. Our gratitude is also extended to the owners and personnel of the collaborating dairy for allowing us access to their cows and facilities to conduct this research.

\section{REFERENCES}

Alkar, A., A. Tibary, J. R. Wenz, R. L. Nebel, and R. Kasimanickam. 2011. Presynchronization with GnRH 7 days prior to resynchronization with CO-Synch did not improve pregnancy rate in lactating dairy cows. Theriogenology 76:1036-1041.

Allison, P. D. 1999. Logistic Regression Using the SAS System: Theory and Application. SAS Institute Inc., Cary, NC.

Bruno, R. G. S., A. M. Farias, J. A. Hernández-Rivera, A. E. Navarrette, D. E. Hawkins, and T. R. Bilby. 2012. Effect of gonadotropin-releasing hormone or prostaglandin $\mathrm{F}_{2 \alpha}$-based estrus synchronization programs for first or subsequent AI in lactating dairy cows. J. Dairy Sci. 95(Suppl. 1):64. (Abstr.)

Cerri, R. L. A., H. M. Rutigliano, R. G. S. Bruno, R. C. Chebel, and J. E. P. Santos. 2005. Effect of artificial insemination (AI) protocol on fertilization and embryo quality in high-producing dairy cows. J. Dairy Sci. 88(Suppl. 1):86. (Abstr.)

Cerri, R. L. A., H. M. Rutigliano, R. C. Chebel, and J. E. P. Santos. 2009. Period of dominance of the ovulatory follicle influences embryo quality in lactating dairy cows. Reproduction 137:813-823.

Chebel, R. C., J. E. P. Santos, R. L. A. Cerri, K. N. Galvão, S. O. Juchem, and W. W. Thatcher. 2003. Effect of resynchronization with GnRH on day 21 after artificial insemination on pregnancy rate and pregnancy loss in lactating dairy cows. Theriogenology 60:1389-1399.

Chebel, R. C., J. E. P. Santos, R. L. A. Cerri, H. M. Rutigliano, and R. G. S. Bruno. 2006. Reproduction in dairy cows following progesterone insert presynchronization and resynchronization protocols. J. Dairy Sci. 89:4205-4219.

Chebel, R. C., A. A. Scanavez, P. B. Silva, J. G. N. Moraes, L. G. D. Mendonça, and G. Lopes Jr. 2013. Evaluation of presynchronized resynchronization protocols for lactating dairy cows. J. Dairy Sci. 96:1009-1020.

Denicol, A. C., G. Lopes Jr., L. G. D. Mendonça, F. A. Rivera, F. Guagnini, R. V. Perez, J. R. Lima, R. G. S. Bruno, J. E. P. Santos, 
and R. C. Chebel. 2012. Low progesterone concentration during the development of the first follicular wave reduces pregnancy per insemination of lactating dairy cows. J. Dairy Sci. 95:1794-1806.

Dewey, S. T., L. G. Mendonça, G. Lopes Jr., F. A. Rivera, F. Guagnini, R. C. Chebel, and T. R. Bilby. 2010. Resynchronization strategies to improve fertility in lactating dairy cows utilizing a presynchronization injection of $\mathrm{GnRH}$ or supplemental progesterone: I. Pregnancy rates and ovarian responses. J. Dairy Sci. 93:4086-4095.

Ferguson, J. D., D. T. Galligan, and N. Thomsen. 1994. Principal descriptors of body condition score in Holstein cows. J. Dairy Sci. 77:2695-2703.

Fitzpatrick, S. L., D. L. Carlone, R. L. Robker, and J. S. Richards. 1997. Expression of aromatase in the ovary: Down-regulation of mRNA by the ovulatory luteinizing hormone surge. Steroids 62:197-206.

Folman, Y., M. Rosenberg, Z. Herz, and M. Davidson. 1973. The relationship between plasma progesterone concentration and conception in post-partum dairy cows maintained on two concentrations of nutrition. J. Reprod. Fertil. 34:267-278.

Giordano, J. O., M. C. Wiltbank, J. N. Guenther, M. S. Ares, G Lopes Jr., M. M. Herlihy, and P. M. Fricke. 2012. Effect of presynchronization with human chorionic gonadotropin or gonadotropinreleasing hormone 7 days before resynchronization of ovulation on fertility in lactating dairy cows. J. Dairy Sci. 95:5612-5625.

Kaplan, E. L., and P. Meier. 1958. Nonparametric estimation from incomplete observations. J. Am. Stat. Assoc. 53:457-481.

Kasimanickam, R., J. M. Cornwell, and R. L. Nebel. 2005. Fertility following fixed-time AI or insemination at observed estrus in Ovsynch and Heatsynch programs in lactating dairy cows. Theriogenology 63:2550-2559.

Kuehl, R. 1994. Complete block designs. Pages 256-305 in Statistical Principles of Research Design and Analysis. Wadsworth Publishing Co., Belmont, CA.

Lopes, G., Jr., J. O. Giordano, A. Valenza, M. M. Herlihy, J. N. Guenther, M. C. Wiltbank, and P. M. Fricke. 2013. Effect of timing of initiation of resynchronization and presynchronization with gonadotropin-releasing hormone on fertility of resynchronized inseminations in lactating dairy cows. J. Dairy Sci. 96:3788-3798.

Macmillan, K. L., V. K. Taufa, D. R. Barnes, A. M. Day, and R. Henry. 1988. Detecting estrus in synchronized heifers-using tailpaint and an aerosol raddle. Theriogenology 30:1099-1114.

Mann, G. E., M. P. Green, K. D. Sinclair, K. J. Demmers, M. D. Fray, C. G. Gutierrez, P. C. Garnsworthy, and R. Webb. 2003. Effects of circulating progesterone and insulin on early embryo development in beef heifers. Anim. Reprod. Sci. 79:71-79.

Mann, G. E., and G. E. Lamming. 2001. Relationship between maternal endocrine environment, early embryo development and inhibition of the luteolytic mechanism in cows. Reproduction 121:175-180.

Mendonça, L. G. D., S. T. Dewey, G. Lopes Jr., F. A. Rivera, F. Guagnini, J. Fetrow, T. R. Bilby, and R. C. Chebel. 2012. Effects of resynchronization strategies for lactating Holstein cows on pattern of reinsemination, fertility, and economic outcome. Theriogenology $77: 1151-1158$

Minitab Inc. 2000. MINITAB Reference Manual. Release 13.32. Minitab Inc., State College, PA.

Moreira, F., R. L. de la Sota, T. Diaz, and W. W. Thatcher. 2000. Effect of day of the estrous cycle at the initiation of a timed artificial insemination protocol on reproductive responses in dairy heifers. J. Anim. Sci. 78:1568-1576.

NRC. 2001. Nutrient Requirements of Dairy Cattle. 7th ed. Natl. Acad. Press, Washington, DC.

Pfeifer, L. F. M., R. Sartori, I. Pivato, R. Rumpf, G. P. Nogueira, E. G. Xavier, N. J. L. Dionello, and M. N. Corrêa. 2009. Effect of circulating progesterone on in vitro developmental competence of bovine oocytes. Anim. Reprod. 6:473-480.

Rivera, F. A., L. G. Mendonça, G. Lopes Jr., J. E. Santos, R. V. Perez, M. Amstalden, A. Correa-Calderón, and R. C. Chebel. 2011. Reduced progesterone concentration during growth of the first follicular wave affects embryo quality but has no effect on embryo survival post transfer in lactating dairy cows. Reproduction 141:333-342.

Ryan, D. P., E. Kopel, M. P. Boland, and R. A. Godke. 1991. Pregnancy rates in dairy cows following the administration of a $\mathrm{GnRH}$ analogue at the time of artificial insemination or at mid-cycle post insemination. Theriogenology 36:367-377.

SAS Institute. 2008. SAS 9.2. Version 3. SAS Institute Inc., Cary, NC

Silva, E., R. A. Sterry, D. Kolb, M. C. Wiltbank, and P. M. Fricke 2007. Effect of prostaglandin $\mathrm{F}_{2 \alpha}$ before resynchronization of ovulation on fertility of lactating dairy cows. J. Dairy Sci. 90:5509 5517.

Vasconcelos, J. L. M., R. W. Silcox, G. L. M. Rosa, J. R. Pursley, and M. C. Wiltbank. 1999. Synchronization rate, size of the ovulatory follicle, and pregnancy rate after synchronization of ovulation beginning on different days of the estrous cycle in lactating dairy cows. Theriogenology 52:1067-1078. 